HID 44 (2017)

\title{
CÍRCULOS DE PODER EN EL MUNDO NOBILIARIO: LINAJE, CONFLICTO Y MAYORAZGO. EL CASO DE LA FAMILIA OROZCO EN LA SEVILLA DEL XVIII ${ }^{1}$
}

\author{
POWER IN ARISTOCRATIC CIRCLES: \\ LINEAGE, CONFLICTS AND ENTAIL. THE CASE OF THE OROZCO \\ FAMILY IN 18TH CENTURY SEVILLE
}

\author{
Isabel Ma Melero MuÑoz ${ }^{2}$ \& Víctor Daniel Regalado GonzÁlez-Serna \\ Universidad de Sevilla \\ imelero1@us.es \\ victordanielregalado@gmail.com
}

RESUMEN: El estudio de la familia Orozco en el escenario sevillano permite acercarnos a un modelo social frecuente en la sociedad moderna: el ascenso y carrera de las familias nobiliarias. Los Orozco muestran el prototipo social de enriquecimiento, obtención de beneficios eclesiásticos, acumulación de títulos nobiliarios, riqueza y poder. La máxima manifestación de esto será la fundación del mayorazgo Orozco-Ayala y que más tarde propició diversos conflictos familiares. El pleito por la sucesión del mayorazgo demuestra la ambición presente en las familias del momento por el dominio del linaje y además estuvo protagonizado por tres individuos que representan un interesante perfil que enriquece con creces este análisis: una mujer, un clérigo y un descendiente natural de este.

PALABRAS ClAVE: Orozco; mayorazgo; Sevilla; pleito; sucesión; linaje.

ABSTRACT: The study of the Orozco family in Seville allows us to better understand a social model that is frequent in Modern society: the rise to power of aristocratic families. The Orozco family are a typical example of such prosperity. They accumulated wealth and power, titles of nobility and ecclesiastical benefits, all of which culminated in the foundation of the Orozco-Ayala entail. This was later to produce many family conflicts relating to the inheritance. In

1. Abreviaturas utilizadas: Archivo Catedral de Sevilla ACS; Archivo Histórico Provincial de Sevilla AHPS; Archivo General del Arzobispado de Sevilla AGAS; Biblioteca Universidad de Sevilla, Fondo Antiguo BUS FA; Archivo Parroquial de San Lorenzo (Sevilla) APSL.

2. Beneficiaria de una ayuda FPU del Ministerio de Educación, Economía y Cultura (Ref. FPU15/02656). Miembro del equipo de trabajo del Proyecto de $\mathrm{I}+\mathrm{D}+\mathrm{i}$ "Andalucía en el mundo atlántico: actividades económicas, realidades sociales y representaciones culturales, siglos XVI-XVIII" (HAR2013-41342-P), financiado por el Gobierno de España. 
this particular case, three people were involved in the dispute: a woman, a priest and his illegitimate descendent.

KEYWORDS: Orozco; entail; Seville; lawsuit; succesion; lineage.

\section{INTRODUCCIÓN}

El objetivo de este trabajo ha sido estudiar la familia Orozco, asentada en Sevilla al menos desde el siglo XVII, puesto que responde al prototipo familiar nobiliario de la Edad Moderna ${ }^{3}$. Los Orozco adquirieron y acumularon una fortuna considerable, lo que les permitió realizar el proceso de reconversión de su riqueza en bienes más honorables para así ascender en la escala social. Las relaciones mercantiles con las Indias permitieron el enriquecimiento de la familia y pronto pudieron extender su red de influencia hacia los diferentes elementos de acumulación de poder: obtención de títulos nobiliarios, acceso al alto clero urbano, poder municipal, etc., cuya máxima expresión fue la fundación de un mayorazgo que permitió la conservación del patrimonio y el estatus del linaje ${ }^{4}$. El poder alcanzado por los Orozco despertó el interés y ambición de los miembros de la familia, que se vieron envueltos en un pleito por la sucesión en el vínculo, ya que implicaba el beneficio económico y control social del linaje ${ }^{5}$. El conflicto que analizaremos por el mayorazgo Orozco-Ayala presenta unos protagonistas con unos perfiles que, además de variados - una mujer, un clérigo y un descendiente natural-son interesantes, ya que nos permite el análisis de los discursos que sostuvieron durante el litigio. Cada uno de los tres pleiteantes defendió su legitimidad para suceder en el vínculo y obtener el control económico familiar. De esta forma, por su encuadre en el modelo social de la modernidad se convierte en un ejemplo muy interesante que abordar y presentar como ejemplo de estudio.

Por otro lado, la metodología utilizada ha consistido en una profunda labor de búsqueda de protocolos notariales que han dado como resultado una variada tipología documental: testamentos, codicilos, poderes, pagos, cartas de arrendamiento e inventarios de bienes. Además, se ha procedido al estudio de la escritura

3. El linaje de los Orozco tiene sus orígenes en siglos anteriores a los que dedicamos nuestro trabajo, en el que nos centramos en el desarrollo de la familia a partir de la segunda mitad del siglo XVII. Existe una amplia bibliografía que nos permite acercarnos a los orígenes del linaje, véase Díaz de Noriega 1976, vol. I, p. 214; vol. II, pp. 150-152; vol. III, pp. 123-126; véase también VV.AA. 2009.

4. La movilidad social en el Antiguo Régimen ha sido un hecho que se ha constatado por diferentes estudios, la burguesía que se fue enriqueciendo mimetizó los usos nobiliarios, para ascender en la escala social. La bibliografía sobre este tema es muy extensa, sólo mencionaremos algunos de los títulos más destacados: Atienza Hernández 1987; Palencia Herrejón 2002; Pérez Álvarez 2004; Soria Mesa 2004; Iglesias Rodríguez 2008; Imízcoz Beunza 2008; Molina Puche 2009; Girón Pascual 2010; Sánchez-Montes González, Lozano Navarro, Jiménez Estrella 2016.

5. Los mayorazgos generaron una fuerte litigiosidad en la Edad Moderna, numerosas familias se vieron envueltas en pleitos por la posesión del vínculo. Algunos ejemplos de estudios sobre esta temática son los siguientes: Montilla García 1986; Carmona Ruiz 2009; Melero Muñoz 2016. 
fundacional del mayorazgo y los documentos jurídicos y defensas legales referentes al pleito por la sucesión en el vínculo. Por otra parte, también se ha recurrido a la documentación eclesiástica como expedientes matrimoniales y pruebas de limpieza de sangre, lo que ha facilitado contar con una rica fuente documental que ha sustentado y permitido, tras el oportuno proceso crítico, la reconstrucción de esta historia. Por supuesto, se ha utilizado la bibliografía pertinente, pero la diversidad documental y la abundante documentación son las piezas claves que han permitido seguir las huellas y movimientos de la familia Orozco durante el siglo XVIII en Sevilla.

En este trabajo, primeramente, trazaremos un perfil de los personajes principales de la familia y que son fundamentales para entender la batalla legal propiciada para la ostentación del poder. Para comprender el calado económico de los Orozco analizaremos brevemente los bienes vinculados en el mayorazgo original, así como todas las agregaciones y acrecentamiento posteriores, que por no engrosar las páginas de este artículo aparecen representados en una tabla en los apéndices. Tras dibujar los perfiles y ubicar a los personajes y su situación dentro del entramado familiar, nos dispondremos a realizar un estudio minucioso del pleito por la sucesión del mayorazgo analizando las defensas legales de cada uno de los protagonistas del conflicto. Una vez presentado el pleito, realizaremos un recorrido por la situación de los personajes tras el proceso judicial y sus nuevas aspiraciones, para terminar con las conclusiones de este estudio.

\section{AMbición y PODER: LOS PROTAGONISTAS DEL LiNAJE OROZCO A FINES DEL XVIII}

La primera cuestión que debemos abordar es la presentación de los protagonistas que estuvieron envueltos en la trama familiar, la acumulación de riquezas y cómo internamente aparecieron personajes que aspiraron a controlarla, conservarla y acrecentarla. De esta forma, nos centraremos en los miembros de la familia que participaron directa o indirectamente en el conflicto por la sucesión del mayorazgo. Por una parte, Juan de Orozco, prebendado de la Catedral de Sevilla que tuvo una hija natural, Ramona de Orozco, la cual jugó un papel fundamental. Por otro lado, haremos referencia a Salvadora de Orozco, hermana del susodicho Juan de Orozco, y que tuvo especial protagonismo en la historia familiar, ya que fue la que obtuvo la tenuta del mayorazgo Orozco-Ayala. Veamos entonces el perfil de estos personajes y sus redes de influencias.

El primer personaje que vamos a presentar es Juan Fernández de Orozco y Manrique, que nació en Sevilla y fue bautizado en la parroquia de San Vicente el día 25 de julio de $1714^{6}$. Siendo clérigo de menores órdenes, recibió el 21 de octubre de 1747 la provisión de una media ración en el Cabildo de la Catedral

6. ACS, I, Secretaría, Pruebas de limpieza de sangre, letra $\mathrm{J} \mathrm{n}^{\circ} 139$, f. $46 \mathrm{r}$. 
de Sevilla ${ }^{7}$. Ya en 1764 fue promovido a una ración, prebenda que mantuvo hasta su fallecimiento ${ }^{8}$. Murió en Sevilla el 23 de enero de 1787 contando 73 años de edad $^{9}$, en su testamento ordenó ser sepultado en la Catedral de Sevilla, en el lugar donde dispusiese el Cabildo ${ }^{10}$. Nada sabríamos de la relación entre Juan de Orozco y su hija, Ramona de Orozco, de no ser porque éste la reconoció como tal el 18 de mayo de 1780 en su testamento nombrándola además su heredera universal, declarando en la tercera manda de la disposición testamentaria lo siguiente:

"Ítem, declaro que antes de estar ordenado in sacris tube una hija que al presente vive y se llama $D^{a}$. Ramona de Orozco, muger legítima que es de D. Francisco María Lobillo, vecina de esta ciudad, la qual será de hedad de treinta y cinco años poco más o menos, por haverla havido en muger soltera, estando yo soltero y libre como llevo declarado sin que entre los dos huviese canónico impedimento, a la qual, conforme a la Ley de Toro la reconozco por tal mi hija natural." 11

De esta manera el propio Juan de Orozco explicó que tuvo a su hija antes de iniciar la carrera eclesiástica. No sabemos si sentía la necesidad de conciencia de reconocerla como tal o si el desencadenante de ello fue el poder situarla y darle legitimidad en el conflicto desatado por la posesión del vínculo fundado por Jerónimo de Orozco y Juliana de Ayala, que abordaremos más abajo. Apenas tres meses después de otorgar testamento, y reconocer la paternidad de Ramona, Juan de Orozco expidió unos poderes para Madrid con el objetivo de conseguir la aceptación de legitimidad de su hija para que pudiera ser la siguiente poseedora del citado mayorazgo ${ }^{12}$. Además, en dichos poderes Juan amplió la información sobre Ramona al indicar que "antes de assender a las sagradas órdenes hube en $D^{a}$. María de Rivera y Casaus, soltera con quien tenía tratado contraer legítimo matrimonio y lo suspendí con su permiso después, por haver conseguido mi prevenda, a $D^{a}$. Ramona de Orozco"13. De esta forma, la causa de la ruptura de este compromiso matrimonial fue la promesa de recibir una prebenda en la Catedral de Sevilla, para lo que previamente Juan de Orozco recibió las menores órdenes entre 1745 y 1747, año en el que accedió a la media ración. Así, argumentó que el reconocimiento de su hija fue dotarla de legitimidad y dejar fundada su línea de descendencia. En este aspecto cobró especial relevancia Juan María Lobillo, hijo de Ramona de Orozco y por lo tanto nieto de Juan de Orozco, el cual pretendió suceder en el mayorazgo familiar incluso pleiteando contra su abuelo.

Respecto a la ruptura del matrimonio que Juan tenía acordado no supuso un gran conflicto, sino que por el contrario, debió negociarse una disolución pacífica del proyecto matrimonial. Esto lo apunta el testimonio a favor de Juan de Orozco

7. ACS, I, Secretaría, Personal, lib. 384, f. 78r.

8. ACS, I, Secretaría, Personal, lib. 384, f. 62r.

9. ACS, I, Secretaría, Personal, lib. 384, f. 62r.

10. AHPS, Protocolos, leg. 9.575, f. 273r.

11. AHPS, Protocolos, leg. 9.575, f. 273r.

12. AHPS, Protocolos, leg. 9.575, f. 532r.

13. AHPS, Protocolos, leg. 9.575 , f. 532 r. 
que realizó Francisco de Rivera Soto y Casaus en las pruebas de limpieza de sangre que se le hicieron en 1748 para acceder a su prebenda ${ }^{14}$. Si la relación de ambas familias se hubiera resentido, obviamente no se hubiera procedido a este testimonio favorable, por lo que debió llegarse a algún tipo de acuerdo. No obstante, se trataba de un enlace conveniente para Juan de Orozco porque lo vinculaba con otra importante familia de la ciudad. Sin embargo, la obtención de la prebenda y el acceso de un miembro de los Orozco al Cabildo de la Catedral de Sevilla suponía un negocio más ventajoso para el conjunto del grupo. A pesar de tratarse de una prebenda menor el hecho de ser nombrado medio racionero significaba la colocación de un miembro de la familia en el alto clero de la ciudad, lo cual resultaba fundamental porque acrecentaba su ámbito de influencia.

En cuanto a la hija de Juan de Orozco, Ramona, fue bautizada en San Juan de Acre el 9 de marzo de $1745^{15}$. Aunque desconocemos la data de su muerte sí sabemos que debió sobrevivir al menos hasta el 26 de abril de 1802, contando 57 años, fecha de su último documento notarial localizado ${ }^{16}$. Como ya hemos comentado, la primera prueba documental que atestiguó su relación con Juan de Orozco fue el testamento de éste. Sin embargo, la documentación ha permitido trazar un perfil sobre Ramona bastante completo salvo en su niñez, período considerablemente oscuro. Sabemos que debió mantener cierta relación con su madre, María de Rivera y Casaus, ya que ésta en 1776 fue madrina de la hija de Ramona, su nieta, aunque no se mencionó el parentesco en la partida bautismal. En dicha partida Ramona aparece además con su apellido paterno, aunque aún faltasen cuatro años para ser reconocida ${ }^{17}$. Esto no es asunto baladí, la utilización del apellido Orozco por parte de Ramona le otorgaba poder para pleitear y declarar sus derechos sucesorios como hija de Juan de Orozco. Además, debemos tener en cuenta que uno de los métodos más utilizados en la Edad Moderna para el ascenso social fue la usurpación de los apellidos, ya que podían llevarse a cabo con relativa facilidad dado el vacío legislativo al respecto ${ }^{18}$.

Ramona de Orozco contrajo matrimonio en primeras nupcias en 1768 con Francisco María Lobillo, enviudando en 1782, volviendo a casarse poco tiempo después con Ramón de Ortega, concretamente en febrero de $1783^{19}$. Solamente tuvo descendencia con su primer marido, teniendo a su primogénito Juan María

14. Desconocemos el grado de parentesco que mantenía con María Rivera de Casaus pero sabemos que el testigo contaba 85 años de edad, por lo que podría tratarse de su abuelo.

15. "En martes nueve de marzo de mil setecientos y quarenta y sinco años, yo frai Juan Suárez del orden de Predicadores, cura y teniente de prior de la Iglesia Parroquial de San Juan de Acre, intramuros de Sevilla, baptizé a Ramona Ildephonsa María de la Paz, hija natural de Don Juan Enrique de Orozco y Doña María de Rivera y Cassaus, vecinos de esta ciudad, nació esta niña el día veinte y tres de enero del citado año. Fue su padrino Don Blas Suárez, vecino de la collación de Omnium Santorum de esta ciudad, a quien advertí del parentesco espiritual y demás obligación, fecho ut supra [rúbrica del sacerdote]" en APSL, caj. 2, lib. 4, f. 122v.

16. Se trata de un poder para pleitos en la Real Audiencia de Sevilla el 26 de abril de 1802 AHPS, Protocolos, leg. 9.589, f. 506r.

17. AGAS, Vicaría General, Expedientes matrimoniales ordinarios, caj. 05832, f. 7r

18. Soria Mesa 2009.

19. AGAS, Vicaría General, Expedientes matrimoniales ordinarios, caj. 1051, f. 1r. 
Lobillo en el año 1771, el cual tuvo gran importancia dentro del conflicto que abordamos, María Josefa en 1777 y José María en $1782^{20}$. Su primer marido no dejó ningún caudal al fallecer. El segundo había sido durante siete años militar sirviendo en el Regimiento de Caballería de Farnesio, y llevaba ya unos once años retirado cuando contrajo matrimonio con Ramona ${ }^{21}$. Cabe reflexionar sobre la situación económica de Ramona, la cual sabemos que no era muy boyante hasta que heredó el caudal de su padre, que al ser nombrada única heredera le garantizó que recibiera al menos sus bienes, ya que el primer marido no le aportó demasiado. Sí se percibe cómo mejoró un poco su situación social al contraer segundas nupcias con un militar retirado, pero sin parecer que tampoco resultara un matrimonio demasiado ventajoso. Por tanto, frente a la situación de la familia Orozco encontramos a Ramona de Orozco olvidada hasta el momento y apartada de la red de influencia del linaje. Esto explica la existencia de la ambición por parte de Ramona para ascender social y económicamente, muestra de ello fue la batalla legal que inició en cuanto fue reconocida por Juan de Orozco, como decimos, con el objetivo de conseguir el ascenso socioeconómico. No debe extrañar la existencia de ambición puesto que había mucho en juego, desde lo honorífico de contar con un título nobiliario hasta los elevados frutos económicos que se extraían de los diferentes mayorazgos familiares.

La ambición no fue el único rasgo marcado del perfil de Ramona, ya que sabemos que además debió de ser una mujer de carácter fuerte. Esto lo atestigua la controversia surgida en 1799 a causa del matrimonio de su hija María Josefa con el abogado de la Real Audiencia de Sevilla Honorio María de Muro y Cote Cos $^{22}$ Los rumores y la polémica surgida de este acontecimiento fueron reseñables, quizás todo provocado porque Ramona no consideraba que fuera un matrimonio adecuado para su hija; aspecto entendible si tenemos en cuenta la pretensión de ascenso social y económico que mantenía Ramona de Orozco. A pesar de que el derecho canónico permitía la libertad matrimonial ya en el siglo XVIII, dándosele incluso la razón judicial a los contrayentes, el permiso paterno seguía contando con gran valor y su negativa podría ser concluyente en numerosos $\operatorname{casos}^{23}$. En este caso, la oposición al enlace fue rotunda, tal como declararon los contrayentes:

"Serles mui dificil practicarlo [el matrimonio] en los términos, condiciones y según se ovserva en los despachos secretos que solicitan por las mui graves y poderosas razones de que $D^{a}$. Ramona de Orozco, D. Juan María Lovillo y D. Ramón de Ortega, madre, hermano y padrastro de la que expone como opuestos todos a que el matrimonio de los que suplican se verifique que por esto han hecho quantas peticiones son incomprehensibles que la han sujerido, violentado y estrechado en

20. AHPS, Protocolos, leg. 9.578, f. 422r.

21. AGAS, Vicaría General, Expedientes matrimoniales ordinarios, caj. 1051, f. 1r.

22. AGAS, Vicaría General, Expedientes matrimoniales ordinarios, caj. 05832, ff. 1r - 10v.

23. Sabemos que la concepción de la Iglesia sobre el amor y la libertad del matrimonio se contraponía a la visión aristocrática para la que el casamiento establecía el orden social y alianzas políticas o económicas con otros linajes, sobre este aspecto véase: Gil Ambrona 2008, p. 64. Además, la legislación sobre el matrimonio cambió a partir del Concilio de Trento, véase: Bonfield 2002, p. 172. 
términos que han sido preciso demandar judicialmente la que expone a su madre, que el que representa ha sufrido varios insultos en repetidas ocasiones de los dichos Lovillo y Ortega, que todos los barrios inmediatos, con especialidad el de San Vicente y San Lorenzo están escandalizados con las habladurías e injusto modo de proceder de la familia de la que expone y últimamente ser esperándose como no podrá menos unos perjuicios acaso irreparables si alguno de la dicha familia llega a imponerse en las diligencias que se hayan de efectuar... "24

El celo demostrado por Ramona para impedir el matrimonio se palpa en todo momento, ya que procuró con ahínco que no se cumpliera y escapara a su control previo. Fundamentalmente, la problemática era que de esta forma Ramona perdía un capital social importante para sus aspiraciones, la boda de su única hija. A pesar de que los contrayentes intentaron aplicar todo el secreto posible, Ramona pretendió conocer cada detalle del proceso ya que "todavía la familia subsiste en su contradicción para la que ni por sangre ni por riquezas ni por otro asumpto tienen motivo que le sea mui dificil se le oculte a la madre estas diligencias porque no aparta de sí a su hija ni un instante" ${ }^{25}$. Ante la tenacidad de Ramona, la hija hubo de acudir a la justicia para conseguir la licencia de matrimonio necesaria, que tal como le amparaba la legislación canónica le fue concedida. Sin embargo, aún así Ramona continuó oponiéndose hasta el extremo que, ante lo difícil que era la convivencia entre madre e hija, el futuro yerno hubo de suplicar a la justicia eclesiástica que "quien deba intervenir en ello se pase inmediatamente y ante todas las cosas a las casas de $D^{a}$. Ramona de Orozco y extrayente dellas a la $D^{a}$. María Josefa Lovillo"26. Se agravó aún más la situación, puesto que parece ser que Ramona podría alterar las pruebas y el proceso judicial, por lo que su yerno solicitó que debía ponerse gran cuidado porque "las referidas habilitaciones pueden experimentar algún trastorno permaneciendo en el juzgado porque $D^{a}$. Ramona de Orozco, madre de la $D^{a}$. María Josefa, puede por algún modo adquirirlas como que algunos dependientes de la curia son sus aliados"27, y debía existir tal peligro, ya que el juez eclesiástico no dudó en aplicar las necesarias actuaciones al respecto. A pesar de las vicisitudes el enlace acabó celebrándose finalmente. De esta forma, este suceso doméstico demuestra el fuerte carácter de Ramona y la ambición económica.

Conviene señalar una vez más que Ramona fue nombrada por su padre heredera universal de sus bienes. Juan de Orozco llegó a ser racionero y aunque no poseyó prebendas mayores sí mantuvo un elevado estatus social, al pertenecer al alto clero urbano hispalense ${ }^{28}$. Es decir, Ramona quedó atendida por la herencia de su padre además de los bienes que tomó, al menos durante los últimos años de

24. AGAS, Vicaría General, Expedientes matrimoniales ordinarios, caj. 05832, f. 1r.

25. AGAS, Vicaría General, Expedientes matrimoniales ordinarios, caj. 05832, f. $2 \mathrm{v}$.

26. AGAS, Vicaría General, Expedientes matrimoniales ordinarios, caj. 05832, f. 8v.

27. AGAS, Vicaría General, Expedientes matrimoniales ordinarios, caj. 05832, f. 8v.

28. En el testamento de Diego de Orozco se menciona a Juan, su hermano, como canónigo en AHPS, Protocolos, leg. 9.562, f. 862v. Incluso él mismo se hizo llamar canónigo al otorgar unos poderes judiciales en AHPS, Protocolos, leg. 9.574, f. 111r. Sin embargo, esto debía responder a un error o 
vida de Juan, cuando recibió en donación una propiedad urbana. En este sentido, en el año 1782 Juan donó a su hija "unas casas principales de morada, con agua de pie que tiene [...] en la calle Juan de Burgos [...], se le suma el solar cedido por el Cabildo por un censo perpetuo" 29 , y la razón que lo empujó a ello fue "por el mucho cariño que le tiene y otras justas causas que le mueven a ello" ${ }^{30}$. Ramona vendió estas propiedades en 1802 por 111.981 reales al oidor de la Real Audiencia de Sevilla Bartolomé Romero González, que vivía en dicha casa como inquilino y que todo indica que el fin de aquella propiedad siempre fue el arrendamiento ${ }^{31}$. Así, aunque Ramona nunca igualaría económicamente al resto de familiares, sí que mejoró su situación con el avance de los años al recibir la atención de su padre.

Seguidamente, pasaremos a otra de las partes implicadas en la red de conflictos de los Orozco, Salvadora de Orozco, que como veremos más adelante fue la que obtuvo la posesión del mayorazgo y, por consiguiente, fue el principal objetivo de crítica de sus colitigantes. En cuanto a la juventud de Salvadora de Orozco, no ha dejado mucha constancia en la documentación, por lo que nos es imposible saber su fecha de nacimiento o saber la posición que ocupaba entre sus hermanos ${ }^{32}$. Lo que sí sabemos es que, durante toda su vida, Salvadora se mantuvo en estado honesto, es decir, soltera. Vivió junto a sus hermanos solteros, siendo constante la preocupación de ellos por su hermana, como se pone de manifiesto en los testamentos de Francisco, Diego y Antonio, que otorgaron cantidades importantes a favor de Salvadora de Orozco. Además, en el caso de Diego de Orozco condicionó su herencia a que Juan de Orozco debía continuar viviendo junto a Salvadora, ya que si no se cumplía este requisito el pleno usufructo de sus posesiones pasaría a su hermana hasta la muerte de ésta, y luego los bienes se debían agregar al vínculo principal ${ }^{33}$. Igualmente, Francisco el mayor en su testamento y agregación al mayorazgo dispuso para Salvadora una pensión anual vitalicia de 400 ducados si se mantenía soltera, mandando otra pensión de 300

actitud de ostentación ya que como más arriba se indica Juan fue primero medio racionero y después racionero, sin ser promovido a otras prebendas capitulares de mayor relevancia.

29. AHPS, Protocolos, leg. 9.576, f. 465r.

30. AHPS, Protocolos, leg. 9.576, f. 465v.

31. AHPS, Protocolos, leg. 9.589, ff. 26r - 46v.

32. El mayor de ellos fue Francisco no conociéndose bien el orden del resto y que fueron Diego, Gaspar, Antonio, Juan, Ana, Manuela, Vicenta, Francisca y parece ser otro hermano llamado nuevamente Francisco. Es así ya que Salvadora tuvo mucha relación con Ramón de Orozco, su sobrino, hijo de Francisco, casado, mientras que el hermano mayor, también llamado así, era soltero. Este segundo Francisco fue el único junto a Gaspar que contrajo matrimonio ya que Francisco, el mayor, Diego, Salvadora, Vicenta y Antonio no tomaron estado. Asimismo, Ana y Manuela fueron profesas en el Convento de Santa Clara y Francisca en el de Santa Paula. Por último, Juan, por ser eclesiástico y romper su promesa de casamiento, tampoco llegó a contraer matrimonio. Sí podemos aventurarnos a decir que Gaspar debió ser el segundo hermano varón porque sucedió en el mayorazgo a Francisco el mayor, no pudiéndose conocer el orden del conjunto de hermanos. Esta reconstrucción parcial se ha podido realizar a partir del estudio de varios documentos en AHPS, Protocolos, leg. 9.562, f. 626r; leg. 9.570, ff. 348r - 352v; leg. 9.574, ff. 433r - 436v; leg. 9.577, ff. 334r - 336v.

33. AHPS, Protocolos, leg. 9.573, f. 323r. Se analizará dicho mayorazgo más abajo, véase tabla en apéndice. 
ducados con la misma condición a Antonio $^{34}$. De esta forma, percibimos que existía una convivencia entre los diversos hermanos que no contrajeron matrimonio, preocupándose unos por el sustento y bienestar de los otros, además de mantener una política de mayor concentración de patrimonio manteniendo bajo control el linaje con fomento de la soltería. Sin embargo, el interés económico provocó que se rompiera este statu quo. Poco sabemos de Salvadora hasta el inicio de la batalla legal, manteniéndose en un perfil familiar bajo hasta que llegó el momento de poder tener la posesión de los mayorazgos familiares, dando un paso al frente y situándose a la cabeza de la familia Orozco. Por lo tanto, se hace necesario un breve repaso a la situación económica de la familia además de, un poco más abajo, referir a la fundación del principal mayorazgo, antes de analizar el pleito en el que se vieron envueltos los Orozco.

La posesión del mayorazgo de los Orozco y de otros vínculos menores implicaba una importante cantidad patrimonial, lo que convierte en tarea imposible la estimación exacta del valor de los bienes que estaban en juego. Sin embargo, sí que conocemos los bienes vinculados a los mayorazgos y podemos comprender su alto poder económico, ya que desde la fundación del mayorazgo de Jerónimo de Orozco y Juliana de Ayala ${ }^{35}$ se produjo un proceso de adscripción de diferentes elementos que lo fueron engrandeciendo. Eso sí lo conocemos y podemos entender cómo se produjo una lucha interna dentro del linaje de los Orozco por la posesión de los mismos ${ }^{36}$. Además de bienes honoríficos poseían unas importantes propiedades agrarias integradas por olivar y vid en el Aljarafe, regadío y moreras en Guadix y un cúmulo de pequeñas propiedades en Burgos, lugar de origen de la familia ${ }^{37}$, amén de algunos bienes inmuebles urbanos. La familia Orozco fue protagonista de una temprana bonanza económica motivada por el comercio y los negocios con Indias, lo cual los atrajo a Sevilla ${ }^{38}$, esta relación se mantuvo al menos hasta que surgió el conflicto que desarrollaremos a lo largo de estas páginas. Aunque no podemos detenernos en este aspecto de configuración y acumulación del patrimonio del linaje y su relación directa con las Indias, no podemos dejar de mencionar algunos elementos fundamentales. Por un lado, Gaspar de Orozco, el segundo hermano varón, habitaba en Nueva España. Igualmente, Diego de Orozco recibía remesas de plata presumiblemente como pago por los negocios realizados con Indias, como 6.000 pesos que esperaba en la flota de $1767^{39}$. Evidentemente,

34. AHPS, Protocolos, leg. 9.574, ff. 444r - 444v.

35. Este mayorazgo fue fundado el 14 de junio de 1634, AHPS, Protocolos, leg. 4356, ff. $131 \mathrm{r}-172 \mathrm{v}$.

36. Véase tabla en apéndice.

37. En la escritura fundacional del mayorazgo se hace referencia a este aspecto: "en las montañas de Burgos, heredad de nuestros padres, abuelos y otras ascendentes, que los han tenido y poseido de más de 300 años, son libres por los que los quiere vincular al mayorazgo" AHPS, Protocolos, leg. 4.356, f. $140 \mathrm{r}$.

38. Las relaciones con Indias constituyeron una práctica común en los siglos modernos, lo que permitió el enriquecimiento de numerosas familias, así como el ascenso en la escala social. La historiografía reciente ha dedicado numerosos trabajos en esta línea, algunos de ellos son: García Domínguez 2016; Iglesias Rodríguez 2016; Tapias Herrero 2017.

39. AHPS, Protocolos, leg. 9.562, f. $861 \mathrm{v}$. 
todos estos bienes y movimientos de capital producían unos importantes frutos y rentas tal como sucedía con el oficio de fiel medidor de granos de Écija, agregado por Francisco de Orozco, y que significaba ingresar $4 \mathrm{mrs}$. por cada fanega de cualquier tipo de grano producido en el término de Écija, emblemática población cerealista del valle del Guadalquivir ${ }^{40}$.

De esta manera aclaramos que no era una cuestión de mera supervivencia económica ni una lucha por el sustento más básico, puesto que incluso Ramona recibió a la postre la atención económica de su padre. Nuestros protagonistas, salvo Ramona, estuvieron siempre más que bien posicionados, sobresaliendo unos más que otros, pero lo que diferenciaba en realidad y estaba en juego era la posesión de los diversos mayorazgos a la muerte de Manuel Mariano de Orozco, su último poseedor, y así colocarse como punta del estandarte del linaje.

\section{AlCANZAR EL PODER SOCIOECONÓMICO DEL LINAJE: EL CONFLICTO POR LA SUCESIÓN EN EL MAYORAZGO OROZCO-AYALA}

Como decimos, la máxima expresión de la acumulación de riquezas y poder de los Orozco fue la vinculación de sus bienes en el mencionado vínculo. Los perfiles de los personajes que hemos dibujado anteriormente tuvieron un cariz más, que fue la activa participación en el conflicto por la sucesión del rico mayorazgo Orozco-Ayala fundado un siglo antes del pleito ${ }^{41}$. El proceso tuvo lugar con la muerte del último poseedor del mayorazgo, Manuel Mariano Fernández de Orozco, III marqués del Zaudín ${ }^{42}$. Tras su fallecimiento se desató una tormenta legal derivada del deseo de los tres pleiteantes por disfrutar el mayorazgo, que fueron por una parte Salvadora de Orozco, por otra parte, el prebendado Juan de Orozco y por último, su nieto, Juan María Lobillo, hijo de Ramona de Orozco.

Con la muerte del último poseedor, la administración y tenuta del mayorazgo pasó a Salvadora de Orozco, ya que siguiendo los llamamientos y la línea de sucesión que establecieron Juliana de Ayala y Jerónimo de Orozco en la escritura fundacional del mayorazgo, Salvadora era la candidata más propincua para la sucesión. Pero, pronto sus colitigantes pusieron una demanda con el objeto de

40. AHPS, Protocolos, leg. 9.574, f. 449r.

41. El mayorazgo fue fundado por Jerónimo de Orozco y Juliana de Ayala en 1634, AHPS, Protocolos, leg. 4356, ff. 131r - 172v, y el pleito tuvo lugar en 1780, BUS, FA, A 109/105 (03), BUS, FA, A 109/105 (11), BUS, FA, A 109/105 (15).

42. Debemos señalar que en la documentación se utiliza indistintamente Zaudín y Saudín como consecuencia del frecuente seseo expresado en las fuentes. En estas páginas hemos preferido utilizar Zaudín y mantener la nomenclatura original de la propiedad que dio nombre al marquesado. El título del marquesado fue una concesión de Carlos III en 1763 a Francisco de Orozco, Teniente General de la Real Armada, miembro del consejo Supremo de Guerra, caballero veinticuatro a perpetuidad y llave de gentilhombre de la Cámara de S.M., en VV.AA. 2009, p.912. Francisco de Orozco fue entonces el primer marqués de Zaudín, vinculó el título al mayorazgo, siendo los protagonistas de este trabajo, Juan y Salvadora, hermanos del susodicho Francisco de Orozco, en AHPS, Protocolos, leg. 9,574, f. 443v, y véase tabla p. 27. 
disfrutar del tan preciado vínculo. Salvadora de Orozco manifestó en su discurso legal el asombro que le producía la razón de ser del pleito. Tenemos que tener en cuenta, como luego veremos detenidamente, que sus colitigantes Juan de Orozco y Juan María Lobillo habían sido excluidos de la sucesión, el uno por pertenecer al estamento eclesiástico y el otro por ser un descendiente natural ${ }^{43}$. Y de esta manera expresó su descontento en su defensa legal:

"No creyó jamás Doña Salvadora de Orozco, tener que seguir un pleito sobre la posesión de los Mayorazgos, que fundó Doña Juliana de Ayala, su tercera abuela, por sí, y en nombre de Gerónimo de Orozco, su marido. Era notorio al tiempo que se verificó la vacante, que no había más descendientes legítimos de los Fundadores que Doña Salvadora y su hermano D. Juan de Orozco. Éste estaba expresamente excluido, por presbitero, en la fundación, que es la Ley que rige para la sucesión. Y él mismo se tenía por tal, suponiendo incontestable el derecho de su hermana. Los descendientes de los Naturales, que entonces se conocian, no debian inquietarle, porque sobre estar igualmente excluidos, no podian suceder sino en defecto de los legítimos. Mucho menos podia pensar que D. Juan María Lobillo, contradigiese su posesión como hijo legítimo de Doña Ramona, que ahora se dice hija natural de D. Juan de Orozco, cuando éste no habia tenido por justo declararla por tal, siendo ya ella de edad de 35 años. Pero todas estas esperanzas se frustraron, sin embargo, de ser tan bien fundadas. D. Juan de Orozco variando de dictamen, entró en el empeño de oponerse de su hermana con tanta tenacidad, que no solo la contradijo por sí mismo, sino que declaró por su hija natural a Doña Ramona, para que ella, o su hijo, D. Juan María Lobillo pudieron oponerse también"'44.

Bien es cierto que, si analizamos la escritura fundacional del mayorazgo, se establecieron cláusulas explícitas que manifestaban el deseo de exclusión de religiosos, determinando que la sucesión del vínculo debía hacerse "con condición que no sucedan ni puedan suceder en el dicho mayorazgo clérigo de horden sacro, ni monxa, ni fraile, ni otro ningún relixiosso professo" así como tampoco podrían suceder en el mayorazgo todos aquellos que no pudieran contraer matrimonio y que, por tanto, no pudieran tener descendencia legítima, incluidas las órdenes militares cuyos estatutos prohibiesen tomar estado matrimonial ${ }^{45}$.

Salvadora de Orozco, una vez que se refirió a la cláusula de exclusión impuesta por los fundadores, siguió alegando las múltiples contradicciones en las que había incurrido su hermano Juan de Orozco. Al parecer, tras la muerte de Manuel Mariano Fernández de Orozco, último poseedor del mayorazgo, Juan de Orozco le había dado la enhorabuena a su hermana Salvadora porque sería ella la que ostentaría el mayorazgo. Juan de Orozco la trató de marquesa y la obsequió con un velón de plata $^{46}$. No obstante, tiempo después el prebendado decidió pleitear por la pose-

43. BUS, FA, A 109/105 (03), f. 2r.

44. BUS, FA, A 109/105 (03), f. 2 r.

45. AHPS, Protocolos, leg. 4356, f. 149v.

46. “Luego que llegó a estos Reynos la noticia de la muerte de Don Manuel Mariano Fernández de Orozco, poseedor de los Mayorazgos en questión, dio la enhorabuena [Juan de Orozco] de su sucesión en ellos a su hermana Doña Salvadora, tratándola de Marquesa, y le regaló con este motivo 
sión del mayorazgo poniéndole una demanda el 13 de julio de 1780, desistiendo dieciséis días después, y volviendo al pleito con una nueva demanda del 28 de septiembre de ese mismo año ${ }^{47}$. En este sentido, Salvadora de Orozco pretendió que se confirmara el auto de la sentencia del 5 de octubre de 1780, mediante la cual el alcalde José López de Herrero le había transmitido la posesión y disfrute del mayorazgo a la susodicha. Salvadora, en su defensa, se detuvo en todos los puntos que habían demandado sus colitigantes insistiendo, como no podía ser de otra forma, en la exclusión de ambos y su derecho y legitimidad como sucesora de los bienes del vínculo.

Uno de los principales puntos de fractura a los que hicieron referencia Juan de Orozco y su nieto Juan María de Lobillo fue el exceso de poder que había cometido Juliana de Ayala al excluir a los clérigos, religiosos y naturales. La fundadora, Juliana de Ayala, otorgó el testamento y la fundación del vínculo como albacea y apoderada de su marido Jerónimo de Orozco. Éste había dado dos poderes a su esposa Juliana, uno el 23 de marzo de $1629^{48}$ y el otro del 20 de abril de $1632^{49}$. En ellos nombró a su esposa albacea declarando que ésta tuviese la potestad de realizar el testamento y fundar el mayorazgo con todos los gravámenes y condiciones que quisiera. Además, poseían una Facultad Real del 14 de enero de 1631 que les daba Licencia Real para fundar el mayorazgo de la manera y forma que quisieran ${ }^{50}$. De esta manera, la primera parte del alegato jurídico de Salvadora de Orozco giró en torno a la defensa de la potestad que tuvo Juliana de Ayala para excluir a los religiosos del mayorazgo, ya que ésta poseía la referida Facultad Real ${ }^{51}$.

El otro gran punto de la defensa de Salvadora fue la exclusión de los naturales. Una vez habiéndose referido a la exclusión que tenía su hermano Juan de Orozco por pertenecer al estamento eclesiástico, la fundadora del vínculo había excluido a los descendientes naturales siempre que hubiese herederos legítimos llamados a la sucesión ${ }^{52}$. De esta manera, Juan María Lobillo como descendiente de un natural, su madre Ramona, debía ser excluido de la sucesión del vínculo, ya que Salvadora de Orozco era una heredera legítima y capaz para poseer el mayorazgo. Pero por si el argumento de la exclusión no tuviese suficiente peso, Salvadora de Orozco no dudó en poner en tela de juicio la filiación de la hija de Juan de Orozco y por consiguiente de su nieto Juan María Lobillo. Salvadora recogió en su alegato el testimonio de Juan de Orozco, mediante el cual había declarado que cuando nació Ramona ésta fue conducida a la casa cuna de los ni-

un velón de plata, diciéndole que era alhaja correspondiente a una Marquesa, como confesó bajo de juramento el mismo Don Juan", en BUS, FA, A 109/105 (03), f. 2r.

47. BUS, FA, A 109/105 (03), f. 2v.

48. AHPS, Protocolos, leg. 4356, ff. 134r - 137r.

49. AHPS, Protocolos, leg. 4356, ff. 138r - 141r.

50. La Real Facultad fue concedida por Felipe IV, y data en Madrid, el 14 de enero de 1631 AHPS, Protocolos, leg. 4356, ff. 143r - 144r.

51. BUS, FA, A 109/105 (03), ff. 3v - 6r.

52. BUS, FA, A 109/105 (03), ff. 14r - 18v. 
ños expósitos de Sevilla ${ }^{53}$. Según recordaba Juan de Orozco, la madre de Ramona era María de Rivera y Casaus, que la sacó de la inclusa al día siguiente de dejarla allí. Salvadora en su alegato refirió que, en tal caso de que esto fuera cierto, la partida de bautismo de la parroquia de San Juan de Acre que habían presentado como prueba de filiación no tenía razón de ser porque, por un lado, los infantes de la casa cuna eran bautizados en la Colegial del Salvador, y por otro, la partida de bautismo estaba fechada en 9 de marzo de 1745, a pesar de que Ramona había nacido el 23 de enero de ese mismo año ${ }^{54}$.

Por otra parte, como ya hemos mencionado anteriormente, Juan de Orozco no había reconocido a su hija Ramona hasta 35 años después de su nacimiento. La hija natural del prebendado había nacido en el año 1745, pero ésta no fue reconocida hasta el 18 de mayo de 1780, trece días después de que Salvadora de Orozco pidiera la posesión del mayorazgo ${ }^{55}$. Esta situación levantó sospechas en Salvadora y en ningún momento creyó que Ramona fuese realmente la hija natural de su hermano. Para Salvadora, la aparición de Ramona había sido en aras de perjudicarla en cuanto a la sucesión del mayorazgo, pues si realmente Ramona era la hija de Juan de Orozco no entendía por qué éste no la había reconocido con anterioridad. Salvadora no dudó en apelar así a la conciencia y honorabilidad de su hermano Juan de Orozco:

"El que al tiempo de su nacimiento la puso en la casa de niños expósitos, y ¿en 35 años no halló motivos bastantes, ni de honor, ni de conciencia, para hacer esta declaración? ¿es creible que los hallase repentinamente luego que se trató de la sucesión del Mayorazgo? ¿Habrá tampoco quién pueda persuadirse a que un caballero tan ilustre y distinguido, como Don Juan de Orozco, habia de exponer a Doña Ramona si entonces la tuviese por su hija natural?"56.

Para Salvadora de Orozco, el interés que se desprendía de estas actuaciones fue claro: el anhelo por la posesión del mayorazgo, aunque no llegó a comprender el deseo de su hermano Juan de Orozco de pretender perjudicarla dada la estrecha relación que habían tenido y el cariño que se habían profesado ${ }^{57}$. La explicación que encontró Salvadora, y con la que concluyó su defensa fue que su hermano, debido a lo avanzado de su edad estaba sufriendo pérdidas de memoria, lo que había

53. Sobre la casa de los expósitos de Sevilla, véase Álvarez Santaló 1980.

54. BUS, FA, A 109/105 (03), ff. 16v - 17r. A pesar de esta declaración de Salvadora de Orozco cabe recordar que la partida de bautismo de Ramona presentada en el pleito ha sido localizada en la parroquia de San Juan de Acre con la información referente, véase nota 11.

55. BUS, FA, A 109/105 (03), f. 17r.

56. BUS, FA, A 109/105 (03), f. 18r.

57. De hecho, en el testamento de Salvadora de Orozco de 1785 hizo mención al cariño que le tenía a su hermano Juan de Orozco, aunque no lo nombró como heredero justificándose en que éste ya tenía sustento para su vida: "y no instituyo asimismo por mi heredero al dicho D. Juan de Orozco, mi hermano, mediante a que en la renta de su prebenda tiene la muy suficiente para su decencia y manutención, al cual si no fuera asi lo dejara también por mi heredero por tenerle igual cariño y voluntad que a los demás mis hermanas y sobrino", en AHPS, Protocolos, leg. 9577, f. 336r. 
despertado el interés de algunas personas que habrían utilizado esta enfermedad para manipularlo y perjudicar a Salvadora ${ }^{58}$ :

"Es fácil creer que D. Juan de Orozco tiene perdida la memoria, pues preguntado
¿quándo otorgó el instrumento de declaración? Respondió que no tenía presente
el día, mes, ni año, siendo así que al tiempo desta repuesta no habían pasado
dos meses después del otorgamiento. Pero no hay para que ocurrir a presuncio-
nes, quando el mismo Juan ha confesado su falta de memoria. Preguntando pocos
días después de haber otorgado el poder y pedido la posesión de los Mayorazgos,
¿quién le hablo y aconsejó que lo hiciese?, respondió que entre los que le aconse-
jaron que saliese a defender su derecho fue uno D. Manuel Sánchez de Herrera,
contador de repartimientos, y que por no tener memoria no se acordaba de otros.
En vista desto, se hace más estraño que mientras D. Juan de Orozco tuvo firme su
memoria, y por consiguiente, tendría presente todas las circunstancias necesarias
para declarar o no a Doña Ramona por su hija natural, no lo hiciese, y pasase a
ejecutarlo luego que perdió la memoria. Acaso con igual consejo que el que confie-
sa tuvo para salir al pleyto"s9.

Pero a pesar de que Salvadora de Orozco obtuvo la tenuta del mayorazgo y de las exclusiones que habían realizado los fundadores, estos motivos no impidieron el conflicto y las demandas que impusieron los otros dos protagonistas del pleito. Juan de Orozco, el prebendado, hermano de Salvadora, pretendió suceder en el vínculo por considerarse un candidato hábil y de mejor línea y grado ${ }^{60}$. El presbítero empezó su defensa refiriéndose a la frecuencia con la que se producían los pleitos entre hermanos. Para ello utilizó el símil bíblico de la lucha por la primogenitura entre Esaú y Jacob ${ }^{61}$, con el que pretendía demostrar "quán reñidos y sangrientos han sido siempre por lo común los pleytos entre hermanos y parientes" ${ }^{\prime 2}$. Este encabezamiento bíblico abrió la defensa de Juan de Orozco que se centró en tres puntos principales. En primer lugar, dedicó varios folios a relatar lo odioso e inadecuado que resultaba la exclusión de los clérigos y religiosos de los mayorazgos. En segundo lugar, defendió su varonía como condición cualitativa frente a su hermana Salvadora de Orozco. Para acabar, centró su defensa en su derecho frente a su nieto Juan María Lobillo, ya que Juan de Orozco tenía mayor grado de proximidad con los fundadores. De esta manera, el prebendado se consideró a sí mismo el candidato más hábil para la sucesión en los mayorazgos disputados.

58. No obstante, a pesar de esta declaración de Salvadora de Orozco debemos referirnos al testamento de Juan de Orozco y su codicilo, donde aparece como sano de cuerpo y mente. En el segundo codicilo, de fecha de 8 de junio de 1784, momento en el que ya se había iniciado el pleito, se hizo referencia también a la salud de Juan de Orozco: "a quién doy fe, conozco, y estando con salud y en su acuerdo juicio, memoria y entendimiento" AHPS, Protocolos, leg. 9577, f. 206r.

59. BUS, FA, A 109/105 (03), f. 18r.

60. BUS, FA, A 109/105 (15), f. 12r.

61. Sobre la cuestión de los elementos religiosos en los pleitos de mayorazgos y la utilización de ejemplos bíblicos, véase Melero Muñoz 2016.

62. BUS, FA, A 109/105 (15), f. 3r. 
Como decimos, Juan de Orozco se dedicó a desmontar la validez de la exclusión de los religiosos, en primer lugar, haciendo referencia al exceso de poder que había llevado a cabo Juliana de Ayala como albacea de Jerónimo de Orozco. Este apartado ya lo hemos tratado en la defensa de Salvadora de Orozco, que recordemos justificó el poder de la albacea para disponer las exclusiones y condiciones que quisiera por estar en posesión de una Facultad Real que le otorgó licencia para ello. En cambio, para Juan de Orozco, Juliana de Ayala había traspasado la línea de sus poderes y se refirió a la obligación de los albaceas o comisarios de seguir fidedignamente la voluntad y disposiciones del testamentario, atestiguando que "siendo tan limitadas y estrechas las facultades de los comisarios o cabezaleros para hacer testamentos, que nada más pueden disponer, ordenar, ni hacer, que aquello que especial y señaladamente señaló y mandó en ellos el que le confirió los poderes" $"$. Con esto, Juan de Orozco quiso señalar que el testamentario Jerónimo de Orozco no habría expresado explícitamente su deseo de excluir a clérigos y naturales de la posesión del vínculo:

"No haviendo, pues, expresa voluntad del fundador exclusiva de los clérigos de Orden Sacro, y de los naturales, ni que limite por modo alguno las reglas y principios de derecho, que como va hecho ver, los admite a la sucesión indistintamente y sin dificultad; pues ni una sola palabra se registra en dichos poderes, de donde semejante exclusión pueda deducirse" ${ }^{64}$.

Pero además de cuestionar el poder que tenían los albaceas para disponer la exclusión de los clérigos, Juan de Orozco continuó su defensa asumiendo que sí se considerara que Juliana de Ayala tuvo poder para hacer la exclusión gracias a la Real Facultad que poseía, aun así, la exclusión resultaba odiosa e inapropiada. En su alegato afirmó que "siendo semejantes exclusiones odiosas en algún modo a la religión y contrarias al estado eclesiástico deben detestarse y contemplarse como no puestas, ni escritas, incapaces de obrar efecto alguno en las disposiciones" $"$. Para el prebendado las exclusiones se hacían por el odio al estamento eclesiástico, lo cual era inadmisible y éstas debían anularse y no tener efecto alguno. En cambio, si las exclusiones de los religiosos, como habían tratado de justificar, tenían su razón de ser en la conservación del linaje y no por odio a la religión, Juan de Orozco, basándose en obras de algunos juristas, creyó que los religiosos eran candidatos hábiles para la sucesión:

"aquellos se reducen a que éstas [exclusiones] no se hacen en odio de la religión, ni del Estado, sino por conservar la memoria, explendor y lustre de la familia y linage, y por serle libre a cada uno disponer de sus bienes como quiera y por bien tuviere. Luego siendo tan capaces los Clérigos y Monjes como los seglares, como expresamente lo afirma el Sr. Molina, donde lleva y funda que los Monjes y Monjas

63. BUS, FA, A 109/105 (15), f. 9v

64. BUS, FA, A 109/105 (15), f. 9r.

65. BUS, FA, A 109/105 (15), f. 12r. 
son capaces de suceder en los Mayorazgos, que tienen la precisa condición de Apellido y Armas" $" 66$.

Una vez que manifestó su capacidad para suceder a pesar de pertenecer al estamento eclesiástico, Juan se detuvo en el discurso de la preeminencia del varón. Al ser su hermana Salvadora de Orozco y él de la misma línea y del mismo grado de proximidad con los fundadores, la sucesión debía recaer en él porque era el candidato más hábil y de mejor calidad por su varonía.

"Ha tenido siempre el primer lugar la Linea, y dentro de ellas la calidad del sexo varonil [...]. Desde el principio elemental de esta materia resulta clara la exclusión de la Doña Salvadora, que como Hembra en concurso con su hermano D. Juan, en quien concurre la qualidad, y prerrogativa del sexo, no puede preferirlo ni entrar en la Sucesión por deberse contemplar excluida por la Ley" "67.

Juan de Orozco, habiendo manifestado su capacidad y fundamentando las cualidades que poseía para suceder en el mayorazgo frente a su hermana Salvadora de Orozco, acabó su defensa jurídica haciendo referencia al último de los protagonistas del conflicto, su nieto Juan María Lobillo. Por un lado, no negó su legitimidad reconociendo a Juan María Lobillo como hijo legítimo de su hija Ramona de Orozco, con lo que confirmó el derecho de sucesión que podría tener el susodicho. En cambio, su nieto debía ser el sucesor del mayorazgo después del propio Juan de Orozco dado que éste tenía mayor grado de proximidad con los fundadores ${ }^{68}$. No obstante, como decimos, el prebendado no dudó en defender la legitimidad de su nieto y preferirlo en el orden sucesorio del mayorazgo frente a su hermana Salvadora de Orozco:

"Don Juan María Lobillo y Orosco, pues, aunque éste como varón legítimo viene a suceder a los Fundadores por su propia persona y excluye a la Doña Salvadora por ser de linea preferente, sin que pueda obstarle ni la ilegitimidad de la Madre ni la exclusión del Don Juan, pues aún quando fuera válida, como personalísima no puede transcender ni gravar la línea por quanto viene y pretende la sucesión por derecho propio derivado en él de el mismo Fundador" $"$.

De esta manera, el deseo de disfrute del mayorazgo de los Orozco-Ayala propició el pleito entre los hermanos Juan de Orozco y Salvadora de Orozco, que hasta el momento habían vivido juntos ${ }^{70}$, rompiéndose de esta forma los lazos

66. BUS, FA, A 109/105 (15), ff. 13v - 14r.

67. BUS, FA, A 109/105 (15), f. 5r.

68. BUS, FA, A 109/105 (15), ff. 21r - 22v.

69. BUS, FA, A 109/105 (15), f. 23r.

70. En su codicilo de 1791 Salvadora de Orozco hacía referencia a que había convivido al menos un tiempo con su hermano Juan de Orozco: “Ítem, declaro que todo lo que hay en mi casa es mío propio sin que en ello tenga nadie parte alguna porque al tiempo que se separó D. Juan de Orozco, mi hermano, prebendado que fue de la Santa Iglesia de esta ciudad, de mis casas y compañia y así después se llevó todo lo que tuvo por conveniente y fue su voluntad con lo que quedamos corrientes de todas 
afectivos existentes entre ambos. Aunque, como hemos referido anteriormente, los hermanos no fueron los únicos actores del conflicto, ya que el tercer pleiteante fue Juan María Lobillo, nieto del prebendado Juan de Orozco, que comenzó su defensa justificando su capacidad para suceder en el mayorazgo ya que era menor de edad, pero no por ello se consideraba un candidato menos hábil ${ }^{71}$. Para justificar su minoría de edad y fundamentar su alegato, utilizó ejemplos de las sagradas escrituras en los que los más jóvenes de la familia eran beneficiados de las herencias y mayorazgos:

"Benjamín, que siendo el de más corta edad de los hijos de Jacob en el solemne convite que hace Josef, entonces ya plenipotenciario de Egipto, a todos sus hermanos que abían venido a verle se señaló para con el dicho Benjamín repartiéndole la mayor parte de forma que eccedió a los demás sus hermanos en cinco y finalmente, como otro Jacob, que siendo menor que su hermano Esaú obtuvo el Mayorazgo de su Casa"'72.

Una vez justificada su minoría de edad y fundamentada la capacidad que poseía para administrar y suceder en el mayorazgo disputado, uno de los puntos principales sobre los que versó el alegato de Juan María Lobillo, tal y como hizo su abuelo, fue el exceso de poder que había cometido la comisaria Juliana de Ayala con la exclusión de los naturales en la fundación del vínculo ${ }^{73}$. Ciertamente, en la escritura fundacional del mayorazgo disputado encontramos la siguiente cláusula, "con condición que todos los que vinieren de suceder en este dicho mayorazgo con conformidad de lo dichos llamamientos ayan de ser y sean lexítimos y de lexítimo matrimonio nacidos e procreados no naturales"74. Pero para Juan María Lobillo la voluntad del testador, Jerónimo de Orozco, fue que se fundara un mayorazgo de mejora de tercio y quinto siguiendo las leyes de los mayorazgos españoles, por lo tanto, conforme a las Leyes de Toro esta consideración implicaba que Juliana de Ayala había excedido su poder excluyendo a los descendientes naturales ${ }^{75}$. Juan María Lobillo, especial interesado en este aspecto, hizo referencia a la Ley 27 de Toro que permitía la sucesión de los hijos y descendientes naturales legitimados ${ }^{76}$ :

cuentas como también por lo que respecta al usufructo por iguales partes que gozaban sobre el vínculo que fundó Diego de Orozco, mi hermano, en la villa de Castilleja por lo demás aviéndose satisfecho el dicho D. Juan, mi hermano, de cuanto le correspondía a conforme a lo dispuesto por el referido Diego, mi hermano", en AHPS, Protocolos, leg. 9580, f. 113r. Esto en parte se debía a una condición establecida por Diego de Orozco, hermano de ambos, que dispuso en su testamento la obligación de que Juan y Salvadora vivieran juntos si querían disfrutar a medias del usufructo de un vínculo que fundaba y que finalmente acabaría incorporándose al principal, AHPS, Protocolos, leg. 9570, ff. 348r - 352v.

71. BUS, FA, A 109/105 (11), ff. 3r - 3v.

72. BUS, FA, A 109/105 (11), f. 3r.

73. BUS, FA, A 109/105 (11), f. 4v.

74. AHPS, Protocolos, leg. 4356, f. 146v.

75. BUS, FA, A 109/105 (11), f. 4v.

76. Ley 27 de Toro: "Mandamos, que quando el padre o la madre mejoraren a alguno de sus fijos o descendientes legítimos en el tercio de sus bienes en testamento, o en otra qualquier voluntad, o por contracto entre bivos, que le pueda poner el gravamen que quisiere, assí de restitución como de fideicommiso, y fazer en el dicho tercio los vínculos y submissiones e substituciones que quisieren, 
"La exclusión de los naturales, que no siendo conforme a los poderes que llevaban por norte la ley 27 de Toro, resulta visiblemente el exceso de dicha comisaria pues estando mandado fundar el Mayorazgo conforme a dicha ley, si esta prohíbe excluir a los naturales, antes bien, después de los hijos legítimos, quiere que sucedan y aún los antepone a los ascendientes de lo legitimos y más a los transversales ¿qué más visible puede estar el exceso que causó en la vinculación oponiéndose a la mente del fundador que quiso ajustarse a dicha ley interin con palabras expresas? '77.

Después de que Juan María declarara diferentes argumentos sobre el exceso de poder que había cometido Juliana de Ayala como albacea testamentaria de su marido y fundador del mayorazgo, Jerónimo de Orozco, el litigante asumió que si por algún caso se considerara que la comisaria sí tuvo poder y potestad suficiente para realizar la exclusión de los naturales, debido a que poseía una Facultad Real, dicho gravamen no afectaría a él mismo. Para Juan María, las diferentes exclusiones que habían recaído en sus ascendentes no debían suponerse para su persona ya que él tenía su propio derecho a la sucesión:

"Bajo cuya consideración aunque sin perjuicio de lo fundado, la Doña Juliana no
se huviera excedido y se huviese podido fundar el Mayorazgo en virtud de Facul-
tad Real, excluyendo a clérigos y naturales y con consiguiente inhabilitar a Don
Juan de Orosco por la qualidad de presbytero para poseer y Doña Ramona de
Orosco como natural, nada le obsta al menor porque él desciende del Fundador, a
él le sucede, es legítimo, viene por su propio derecho y Persona, y caso de que no
huviese línea havitual constituida en tiempo abil oy la formaría el menor por su
mejor sexo"78.

Asumiendo este último aspecto, para el menor en cambio no existió abuso de poder por parte de Juliana da Ayala para la exclusión de los religiosos pues determinó que su abuelo, Juan de Orozco, debía estar excluido de la sucesión por su condición de presbítero y de prebendado del Cabildo de la Catedral de Sevilla. No obstante, a pesar de la condición religiosa de su abuelo, Juan María Lobillo asumió su legitimidad, dado que su abuelo había tenido la descendencia antes de entrar en religión:

con tanto lo fagan entre sus descendientes legítimos; e a falta dellos, que lo puedan fazer entre sus descendientes ylegitimos que ayan derecho de les poder heredar; y a falta de los dichos descendientes que lo puedan hazer entre sus ascendientes; e a falta de los susodichos puedan hacer las dichas submissiones entre sus parientes e a falta de parientes entre los estraños; e que de otra manera no puedan poner gravamen alguno ni condición en el dicho tercio. Los quales dichos vínculos e submissiones, ora se fagan en el dicho tercio de mejoría, ora en el quinto, mandamos que valan para siempre o por el tiempo que el testador declare, sin fazer diferencia de quarta ni de quinta generación". Leyes de Toro. Estudio preliminar y transcripción de $M^{a}$ Soledad Arribas; presentación de Ramón Falcón Rodríguez, Madrid, Servicio de Publicaciones del Ministerio de Educación y Ciencia. Secretaría General Técnica, 1977 , p. 52.

77. BUS, FA, A 109/105 (11), f. 5r.

78. BUS, FA, A 109/105 (11), f. 12v. 
"En nuestro caso el don Juan está excluido como Presbytero, pero no haviendo tenido esta exclusión en todo tiempo porque antes fue seglar que clérigo, tuvo oportunidad para fundar su cabeza línea habitual para sus descendientes y la posterior qualidad [presbitero] de que se revistió no puede gravar a la línea"79.

Continuando con la defensa de Juan María Lobillo, otro de los principales puntos que trató fue la prueba de filiación de su madre, Ramona de Orozco, como hija natural de Juan de Orozco. Para ello presentó diferentes documentos e instrumentos que probaban la filiación. En primer lugar, la partida de bautismo de Ramona de Orozco en la que aparecía Juan como padre. Por otro, la partida de casamiento de la susodicha con Francisco María Lobillo. Por último, el reconocimiento del propio Juan de Orozco en el que declaró a Ramona de Orozco por su hija natural tenida de mujer soltera antes del impedimento canónico ${ }^{80}$. Juan María Lobillo pretendió demostrar en su alegato la exclusión de su abuelo Juan de Orozco por pertenecer al estamento eclesiástico, asumiendo por otro lado que su madre, Ramona de Orozco, había sido concebida antes de que su abuelo fuese clérigo. Aclarado este aspecto, el siguiente punto en el que se detuvo el pleiteante fue en la limpieza de su imagen, ya que descendía de una natural y por lo tanto había sido acusado de provenir de una raíz infecta:

"En lo primero confiesa mi cortedad que no puede acomodarse con el nombre de raíz infecta que se le da a la Madre natural respecto de su hijo porque no me parece del todo consonante. Yo llamaría raíz infecta la que tragese uno que desciende de judios, sarracenos, moros o herejes porque esta es odiosa a la familia, y se presume que el testador quiere conservar en su descendencia la pureza de su sangre, el honor y nobleza de su familia y que los sucesores no estén manchados de esta raiz infecta. [...] Pero decirle raiz infecta a la que el padre natural forma [...] no la tengo por tal porque falta la razón de agraviar el honor y la nobleza de la familia, y más en nuestra nación que las mismas leyes lo han ennoblecido tanto""11.

El menor, Juan María Lobillo, no dejó ningún aspecto sin resolver en la defensa jurídica que presentó. Empezó tratando el exceso de poder de la comisaria para realizar la exclusión de los naturales salvaguardando que en el caso de poder realizarlo a él no le afectaba, asumió la exclusión de su abuelo y colitigante por ser clérigo, luego demostró la filiación de su madre Ramona de Orozco y por último afirmó su limpieza y nobleza. Sólo le quedaba alegar contra su tía abuela Salvadora de Orozco, que además había obtenido la tenuta del disputado mayorazgo. Obviamente, entre los argumentos que utilizó Juan María Lobillo para pretender que se apartara a Salvadora de Orozco de la sucesión del vínculo estuvo el discurso de la preeminencia del varón ${ }^{82}$. Pero, por si este argumento no tuviese suficiente peso, Juan María Lobillo no dudó en combatir a su tía abuela en aspectos

\footnotetext{
79. BUS, FA, A 109/105 (11), f. 13r.

80. BUS, FA, A 109/105 (11), ff. 20v - 21r.

81. BUS, FA, A 109/105 (11), ff. 16v - 17r.

82. BUS, FA, A 109/105 (11), f. $3 \mathrm{v}$.
} 
más personales. En su alegato, el menor trató de establecer un "argumentario del miedo" a la pérdida de los bienes del mayorazgo. Hay que tener en cuenta que la fundación del vínculo se realizaba, por un lado, con el objetivo de salvaguardar el patrimonio familiar y por otro, en su aspecto más social por el fin de conservar y perpetuar la memoria del linaje ${ }^{83}$. Ciertamente, en la escritura de fundación del mayorazgo Orozco-Ayala se hizo referencia explícita a la importancia del vínculo como método para que el linaje familiar y su memoria fuese perpetua ${ }^{84}$. En este sentido, siendo Juan María Lobillo consciente de la importancia económica y social que suponía la conservación y perpetuación del mayorazgo, acusó a su tía abuela de ser incapaz de cumplir estos objetivos dada su avanzada edad. Para Juan María Lobillo, si se diese el caso de que Salvadora de Orozco fuese finalmente la sucesora del mayorazgo, se pondría en peligro la descendencia del linaje porque la susodicha era por entonces muy mayor y no podría tener hijos. Así argumentó a favor de la exclusión de Salvadora de Orozco:

"Porque [la sucesión en el mayorazgo] siempre deben empezar por varonía y oy se encuentra para su formación un descendiente varón del fundador. Y más quando la Doña Salvadora por su abansada edad si oy fuese a constituir linea como que no tiene descendientes, ni aún quando se casase los puede tener, si no es por un milagro como Sara, se daría lugar a que ella por su muerte dispusiese de los bienes como libres, lo que debe evitarse como tan recomendado lo contrario, y quedaría postergado un descendiente del fundador que está en actitud de llevar la Casa adelante" $"$.

De esta manera, hemos expuesto brevemente los principales puntos de fractura en el pleito por el rico mayorazgo Orozco-Ayala representado en las tres partes tratadas. El conflicto constituye una clara manifestación del deseo de poseer y disfrutar de los beneficios del mayorazgo rompiendo la armonía familiar de los actores del pleito, que no dudaron en usar diferentes recursos y argumentos legales para deslegitimar a sus colitigantes y así obtener la sucesión y el disfrute del vínculo familiar que, en cualquier caso, era la máxima expresión de la acumulación de poder del linaje.

83. La conservación de la memoria del linaje era objetivo fundamental de la creación de los mayorazgos, razón por la que se imponía en las fundaciones el gravamen de que los sucesores al vínculo debían conservar el apellido y escudo de armas familiar, Clavero 1989, pp. 256-257. En este mismo sentido, en la fundación del mayorazgo que estamos trabajando también aparece el gravamen de armas y apellidos, que versa así: "Que el que suceda en el mayorazgo ya sea hombre o mujer sea del apellido y armas de Orozco y Ayala en primer lugar que otro apellido, aunque sea de varonía. Porque todos sus antepasados y ellos traen sus armas que el que no cumpla la condición del apellido pierda el mayorazgo y pase al siguiente en grado", en AHPS, Protocolos, leg. 4356, ff. 147r-147v.

84. AHPS, Protocolos, leg. 4356, f. 136r.

85. BUS, FA, A 109/105 (11), ff. 18v - 19r. 


\section{SAlVAdora de Orozco IV MARQUESA DEL ZAUdíN: LA SITUACIÓN} DE LOS OROZCO TRAS EL PLEITO DE MAYORAZGO

Una vez comprendida la importancia de la familia Orozco y los intereses que se disputaban conviene dibujar qué sucedió tras el litigio. En primer lugar, tenemos que referirnos a uno de los protagonistas más destacados, Juan de Orozco, el cual falleció en 1787 estando aún activo el pleito por la posesión del mayorazgo. Por otro lado, Salvadora de Orozco cobró un especial protagonismo durante y después del conflicto. De aparecer en la documentación sólo de manera colateral y completamente secundaria, su protagonismo creció considerablemente desde el momento en que se le concedió la tenuta del mayorazgo. De esta forma se había convertido en la cabeza de la familia Orozco, entonces ya muy reducida en miembros, pero no en poder económico. Para la administración del mayorazgo se apoyó bastante en su sobrino Ramón de Orozco, quien ostentando poderes de representación de su tía se encargó activamente de gestionar junto a ella los diferentes bienes familiares. Además, como cabía de esperar por ser una condición de los mayorazgos, tras la sucesión de Salvadora de Orozco se acrecentaron los bienes del mismo ${ }^{86}$. Conocemos todos los bienes que poseía el vínculo Orozco-Ayala en el momento de la posesión y podemos saber cuánto se acrecentó con Salvadora ${ }^{87}$. Finalmente, Salvadora falleció en 1799, volviendo a aparecer entonces nuevos intereses y conflictos.

No podemos dejar de mencionar a otro personaje que ya hemos aludido y que estuvo relacionado con Salvadora de Orozco y empezó a tener protagonismo desde el litigio. Salvadora tuvo una estrecha relación con su sobrino Ramón de Orozco, éste ya fue apoderado de su tía durante muchos años y, en muestra del cariño que le tenía, recibió diferentes mandas testamentarias a su favor, siendo nombrado albacea y también uno de sus herederos ${ }^{88}$. Todo estaba encaminado a que Ramón sucediera a su tía como poseedor de los mayorazgos familiares y ostentara el título de marqués del Zaudín por ser el último familiar directo de sus tíos. Sin embargo, el destino hizo que el 18 de septiembre de 1800 Ramón de Orozco otorgase poderes para que dispusieran su testamento ya que le había sobrevenido una grave enfermedad, de la que presumiblemente no sanó puesto que ni siquiera tuvo fuerzas para firmar dicho poder ${ }^{89}$. Ramón de Orozco no tuvo descendencia, la situación más habitual dentro de su familia, por lo que nombró herederas a sus dos sobrinas, hijas de su difunta hermana ${ }^{90}$. Por tanto, con la muerte de Salvadora de Orozco sin

86. Véase tabla en apéndice.

87. En la escritura fundacional del mayorazgo los fundadores establecieron la condición de que cada poseedor, antes de suceder en el mismo, tenían la obligación de hacer inventario de sus bienes ante un escribano público, además debía beneficiar y arreglar los bienes del vínculo, AHPS, Protocolos, leg. 4356, f. $147 \mathrm{v}$.

88. AHPS, Protocolos, leg. 9.577, ff. $334-336$

89. AHPS, Protocolos, leg. 9.585, ff. 790 - 791.

90. Ramón de Orozco fue religioso alcanzando al menos el grado de menores órdenes en ACS, Capitular, Secretaría, Correspondencia, caj. 12.001, exp. 1, sin foliar 9 de marzo de 1752. 
descendencia y el fallecimiento de su sobrino predilecto, comenzaron de nuevo los pleitos por la sucesión del mayorazgo y control del linaje familiar.

Entonces, la última pregunta que cabe hacernos es ¿qué sucedió con Ramona de Orozco? Hemos podido constatar que días después de la muerte de su primo ella enviudó por segunda vez. Su segundo esposo, Ramón de Ortega, otorgó también poderes para testar a causa de la gravedad de su enfermedad el 26 de septiembre de $1800^{91}$. Nada sabemos después sobre Ramona salvo por la venta de una propiedad en $1802^{92}$, siendo esta la prueba documental más tardía hallada sobre Ramona. Igualmente, tampoco sabemos qué ocurrió con Juan María Lobillo, su hijo, que desapareció de escena tras finalizar el litigio, desconociéndose qué sucedió de él salvo que durante el conflicto por el matrimonio de su hermana en 1799 aún permanecía con vida ${ }^{93}$. En enero de ese mismo año Ramona otorgó poderes judiciales para iniciar la reclamación de posesión del mayorazgo de Guadix fundado por Manuel de Orozco, que había dejado como sucesora a Salvadora de Orozco y por haber ésta fallecido ahora quedaba vacante ${ }^{94}$. Y es que Ramona, a pesar de no vencer el pleito contra su tía, tras la muerte de ésta volvió a pretender la posesión de este mayorazgo menor de Guadix vinculado a los Orozco. Este hecho muestra una última vez cómo la pretensión de Ramona por ascender social y económicamente no cesó con el paso de los años, sino que, más bien, se mantuvo firme hasta el final de sus días.

\section{CONClusión}

El estudio de la familia Orozco ha permitido analizar la importancia de ésta y su papel modelo dentro de la sociedad moderna. Fue una familia que se enriqueció, vinculó sus bienes y luchó por acrecentarlos. Cumplió así con una praxis típicamente nobiliaria extendida en la Edad Moderna. Las fuentes documentales han permitido conocer los entresijos y redes familiares tejidas entre los miembros de la familia nobiliaria. Del mismo modo, el pleito por la sucesión del mayorazgo Orozco-Ayala pone de manifiesto la importancia social y económica que suponía la posesión de un vínculo tan rico como el disputado, de forma que despertó el interés de los protagonistas del conflicto que además se vieron envueltos en una batalla legal. La disputa provocó en algunos casos la ruptura de los lazos familiares que habían mantenido desde antaño, como manifiestan Salvadora y su hermano Juan de Orozco, y en otros casos sirvió para tejer nuevas relaciones familiares, como representa Juan al reconocer e intentar legitimar a su hija Ramona de Orozco y su nieto Juan María Lobillo, que jugaron un papel fundamental en el devenir de la familia. Además, el análisis de las defensas jurídicas de las partes litigantes ha

91. AHPS, Protocolos, leg. 9.585, ff. 805 - 806.

92. Ya analizado más arriba.

93. AGAS, Vicaría General, Expedientes matrimoniales ordinarios, caj. 05832, ff. 1r - 8v.

94. AHPS, Protocolos, leg. 9.585, f. 47. 
permitido profundizar en los discursos y argumentos utilizados por cada protagonista, permitiéndonos conocer mejor el perfil y los intereses que manifestaron.

La posesión de mayorazgos suponía una jugosa atracción para todo aquel que tuviera cierto derecho a poseerlo. Así, en cuanto se encontraba una grieta jurídica las partes interesadas entraban en lucha por su control. No era extraño que esto sucediera en la sucesión de los mayorazgos y, por lo tanto, no lo fue tampoco que en el caso de los Orozco ocurriera lo propio. Una mujer, un clérigo y la hija natural de éste haciendo valer los derechos de su hijo, buscaban el resquicio legal para tener la posibilidad de acceder a la posesión de un mayorazgo que tenía vinculados importantes bienes económicos y honoríficos, como un marquesado. Este aspecto fue suficiente para romper la relación de dos hermanos, Juan y Salvadora. También era suficiente para desatar la ambición de Ramona, mujer de fuerte carácter, y provocar que luchara incansablemente junto a su hijo para hacer valer sus derechos. $\mathrm{Y}$ en este conflicto se recurrieron a todos los medios legales al alcance llegando a convertirse casi en una obsesión.

Para Salvadora de Orozco la posesión del mayorazgo supuso un acrecentamiento económico y una mayor libertad de actuación, pero, no obstante, estaba ya bien situada antes de acceder al mayorazgo principal. No así sucedió con Ramona, que comparativamente era de baja posición por haber nacido fuera del matrimonio siendo relegada de la vida nobiliaria de los Orozco, al menos hasta el momento de ser reconocida por su padre Juan, periodo en el que su suerte pareció cambiar. Esto no fue impedimento alguno para que Ramona luchara por crecer socialmente. No obstante, sí fue heredera de los bienes de su padre, el prebendado Juan de Orozco, lo que permitió que ya en la madurez Ramona garantizara cierta estabilidad económica pero que, sin lugar a dudas, no era comparativamente nada respecto a lo que significaría poseer el mayorazgo Orozco-Ayala. Perder este pleito no supuso la rendición de Ramona. Su ambición era más fuerte y hasta el último momento aprovechó cada oportunidad que tuvo para ascender social y económicamente. Así, Ramona responde a un perfil social muy interesante que refleja una de las problemáticas del Antiguo Régimen, la importancia de la legitimidad social.

En definitiva, el estudio de esta familia permite observar e identificar los distintos círculos de poder propios de las familias nobiliarias, en los que se ponía en juego las redes de influencia para conseguir mantenerse y ascender en la escala social. Con esto, procuraban concertar matrimonios influyentes para los miembros de la familia, conseguir títulos de la nobleza castellana como el Marquesado del Zaudín en el caso de los Orozco y el acceso a posiciones de prestigio en la Iglesia, lo que ampliaba su ámbito de control y dominio. Y por supuesto, proceder a la vinculación de los bienes en un mayorazgo como estrategia para el crecimiento del patrimonio familiar y el mantenimiento del honor y prestigio del linaje. 


\section{APÉNDICE}

\section{Jerónimo de Orozco y Juliana de Ayala. 1634.}

Propiedades en Tomares. ․ - Dos huertas de frutales y un cercado de viñas de 23 aranzadas junto a su casa de Tomares.

- Tierras llamadas Venta Blanca con 1.821 pies de olivos.

- Cuatro pedazos en la vega que hacen 12 aranzadas y que se llaman Haca del Rosario, Haca Conguera, La Cuadrada y La Hijuela.

- Una casa con sus torres y cerca de almenas y portada de piedra con sus armas esculpidas.

- Otra haza de tierras llamada de la Cansa y mayor de 6 aranzadas.

Propiedades en Villaldemiro ${ }^{95}$.

Propiedades en Castrillo de Cabezón ${ }^{96}$.
Cargos.

Activos.
- Una casa principal antigua con las armas de los Orozco esculpidas en piedra en la portada.

- Una suerte de tierra de 8 fanegas.

- Una casa.

- Tierras de 1 fanega llamada La Calera.

- 3 propiedades de 0,5 aranzadas sin identificar.

- $\quad 11$ propiedades de 0,5 fanegas sin identificar.

- 7 propiedades de 1 fanega sin identificar.

- 2 propiedades de 1,5 fanegas sin identificar.

- 3 propiedades de 2 fanegas sin identificar.

- 2 propiedades de 2,5 fanegas sin identificar.

- 1 propiedad de 4 fanegas sin identificar.

- Tierras de 1 fanega llamadas La Cardeñosa.

- Prado de 0,5 fanegas.

- Prado de 4 fanegas.

- 1 aranzada de tierra llamada Arroyo.

- Tierras cercadas de pared de 0,5 fanegas.

- Tierras de 4 fanegas rodeadas por un arroyo.

- Tierras de 1 fanega, es una loma.

- Tierras de 1 fanega, llamada La Hoz.

- Tierras de 3 fanegas, llamada La Coruilla.

- Una huerta de 0,5 fanegas, cercada de piedra, sin árboles, llamada de Casar.

- Una venticuatría de la ciudad de Sevilla.

- $\quad 3.200$ ds. de rédito anual sobre las sisas de Sevilla.

- $\quad 526.000$ mrs. sobre la deuda de Granada junto a otro de $562.500 \mathrm{mrs}$.

- $\quad 375.000$ mrs. más sobre lo anterior.

- En Madrid 343.585 mrs. de renta más otro juro de 3.200 ds.

95. En la documentación no se utiliza Villaldemiro sino variantes de este nombre. Se ha procedido a la identificación gracias a la toponimia expresada en la fundación del mayorazgo.

96. Igual que en el caso anterior en la documentación no se especificaba exactamente el lugar, apareciendo Castrillo pero sin diferenciar entre las diferentes poblaciones con idéntico nombre. Sin embargo, gracias a la toponimia incluida en la fundación ha sido posible la identificación exacta. 
Capilla.

- Patronato de una capilla con entierro en el Convento de San José de la orden de recoletos descalzos de Nuestra Señora de la Merced.

\section{Mayorazgo secundario de feminidad de Jerónimo de Orozco y Juliana de Ayala. 1634.}

Activos.

- Un juro de almorifazgo de $421.085 \mathrm{mrs}$.

- Un juro de almorifazgo de Indias de $50.150 \mathrm{mrs}$.

- Un tributo de 80 ds.

- Un juro de 420.085 mrs.

\section{Agregación de Francisco de Orozco. 1761.}

Propiedades en Sevilla. $\quad$ - $\quad 12.000$ ds. para la compra de una casa en Sevilla.

Propiedades en Tomares. $\quad$ - Hacienda del Zaudín de 128 aranzadas de olivar.

Cargos.

- Oficio de fiel medidor de granos de Écija.

Títulos.

- Marquesado del Zaudín.

\section{Agregación de Antonio de Orozco. 1766.}

Propiedades en Tomares. $\quad$ - 1.500 rs. para la compra de 5 aranzadas de olivar en Tomares.

Agregación de Diego de Orozco. 1774.

Propiedades en Castilleja - Hacienda La Pintada.

de la Cuesta.

Propiedades en Sevilla. $\quad$ - De su caudal que se saque para comprar una casa.

Fundación de Manuel de Orozco ${ }^{97} .1755$.

Propiedades en Guadix. a casa en la Pila Mayor de la Catedral de Guadix.

- Una huerta en la vega con tierras de secano y una cueva, corral y moreras.

Propiedades en Marchal. $\quad$ _ $\quad 1$ fanega de tierra llamada de los Calzoncillos.

- 1 fanega de tierra frente al molino y acequia de Purullena.

- 3 marjales de tierra de regadío en la Mairena.

- 1 fanega en la Rambla del Tejar.

Propiedades en Beas de - 54 arrobas de hoja de moral.

Granada.

- 6 fanegas y 11 celemines de tierra calma de riego.

- 7 fanegas, 2 celemines y 2 cuartillos de tierra de riego en la cañada de Gómez Vega.

- 7 fanegas y 3 celemines, con pozo, que se llama La Solana.

- 4 fanegas y 5 celemines en la cañada de Gómez Vega.

97. Tío paterno de Salvadora, fundó el mayorazgo en Guadix y que, a diferencia de las otras agregaciones, este nuevo vínculo no se unió al principal. En cambio, determinó que Salvadora fuera la primera poseedora. Consideramos importante añadirlo por ser el mayorazgo que reclamará Ramona de Orozco tras fallecer Salvadora de Orozco. 
- Una haza de 3 fanegas de tierra calma junto a la ermita de San Sebastián.

- 3 fanegas de tierra con moreras en el pago de Chitrana.

Agregación de Salvadora de Orozco. 1799.

Propiedades en Sevilla. - Una casa en la calle Acetres.

Propiedades en Castilleja - Una suerte de olivar de 11,5 aranzadas junto a la ermita de la Cuesta. de Nuestra Señora de Guía y llamada La Cantera.

\section{BibLiografíA}

Álvarez Santaló, L.C. (1980), Marginación social y mentalidad en Andalucía Occidental: Expósitos en Sevilla (1613-1910), Sevilla, Consejería de Cultura.

Atienza Hernández, I. (1987), Aristocracia, poder y riqueza en la España Moderna: la Casa de Osuna, siglos XV-XIX, Madrid, Siglo XXI.

Bonfield, LL. (2002), “Avances en la legislación familiar europea”, en Kertzer David, I.; Barbagli, M. (coord.), La vida familiar a principios de la era moderna (1500-1789), Barcelona, Paidós, p. 172.

Carmona Ruíz, MaA A. (2009), "La mentira como arma. Pleitos en torno a la propiedad de un mayorazgo. Nínchez y Chozas (siglo XV-XVI)", Historia. Instituciones. Documentos, 36, pp. 111-135.

Clavero, B. (1989), Mayorazgo. Propiedad feudal en Castilla 1369-1836, Madrid, Siglo XXI.

Díaz de Noriega Pubul, J. (1976), La Blanca de la Carne en Sevilla, Madrid, Editorial Hidalguía, 1976.

García Domínguez, F.J. (2016), "La proyección atlántica de un linaje sevillano: los Saavedra y el Marquesado de Moscoso en el siglo XVII", en Iglesias Rodríguez, J.J.; García Bernal, J.J. (eds.): Andalucía en el mundo Atlántico Moderno. Agentes y escenarios, Madrid, Sílex, pp. 335-354.

Gil Ambrona, A. (2008), Historia de la violencia contra las mujeres. Misoginia y conflicto matrimonial en España, Madrid, Cátedra.

Girón Pacual, R.M (2010), "Patrimonio, mayorazgo y ascenso social en la Edad Moderna”, en Díaz, J.P.; Andújar, F. y Galán, A., Casas, familias y rentas: la nobleza del reino de Granada entre los siglos XV-XVIII. Granada, Universidad de Granada.

Iglesias Rodríguez, J.J. (2008), El árbol de sinople. Familia y patrimonio entre Andalucía y Toscana en la Edad Moderna. Sevilla, Servicio de Publicaciones de la Universidad de Sevilla.

Iglesias Rodríguez, J.J. (2016), "Redes familiares y élites mercantiles internacionales en la Andalucía Atlántica Moderna (Cádiz, siglos XVI-XVII)" en Sánchez-Montes González, F.; Lozano Navarro, J.J.; Jiménez Estrella, A. (eds.), Familias, élites y redes de poder cosmopolitas de la monarquía hispánica en la Edad Moderna, Granada, Comares, pp. 143-170. 
Imízcoz Beunza, J.M (2008), "Familia y redes sociales en la España Moderna”, en La familia en la historia, XVII Jornadas de Estudios Históricos, pp. 135-186.

Melero Muñoz, I.Ma (2016), "El conflicto por el legado de Gaspar de Castro: un pleito de mayorazgo en la Sevilla del siglo XVIII", en García Fernández, M. (ed.): Familia, cultural material y formas de poder en la España Moderna. III Encuentro de jóvenes investigadores en Historia Moderna, Madrid, Fundación Española de Historia Moderna, pp. 515-524.

Melero Muñoz, I.Ma (2016), "La plasmación de los elementos religiosos en los pleitos por mayorazgo: fundaciones, ejemplos bíblicos e ilustraciones en porcones del siglo XVIII" en Eliseo Serrano (ed.), XIV Reunión Científica, Zaragoza.

Molina Puche, S. (2009), “Aristocracia, linaje, mayorazgo: reflexiones a través de la casa de los marqueses de Villena en la Edad Moderna", Familias, jerarquización y movilidad social, Murcia, Universidad de Murcia.

Montilla García, MaA. (1986), "La función de los mayorazgos en la vida social. A propósito del pleito por la herencia del de los Campillos en 1751 en la villa de Medrano", en Segundo Coloquio sobre Historia de La Rioja, 2, pp. 193-198.

Palencia Herrejón, J.R. (2002), “Estrategia patrimonial y jerarquía del linaje: los mayorazgos de la Casa Ducal de Maqueda en el siglo XVI", Historia. Instituciones. Documentos, 29, pp. 337-355.

Pérez Álvarez, Mª. (2004), "Familia y estrategias familiares en el marco de unas estructuras socioeconómicas tradicionales: el modelo de la montaña noroccidental leonesa en la Edad Moderna”, Revista de Demografía Histórica, XXII, pp.121-147.

Sánchez-Montes González, F., Lozano Navarro, J.J. Jiménez Estrella, A. (eds.) (2016), Familias, élites y redes de poder cosmopolitas de la monarquía hispánica en la Edad Moderna, Granada, Comares.

Soria Mesa, E. (2004), “Genealogía y poder. Invención de la memoria y ascenso social en la España Moderna”, Estudis: Revista de Historia Moderna, 30, pp. 20-55.

Soria Mesa, E. (2009), “Tomando nombres ajenos. La usurpación de apellidos como estrategia de ascenso social en el seno de la élite granadina durante la época moderna", en Las élites en la época moderna: la Monarquía española, Córdoba, Universidad de Córdoba, pp. 9-28.

Tapias Herrero, E. (2017), El Almirante López Pintado (1677-1745): el duro camino del éxito en la carrera de Indias, Sevilla, Universidad de Sevilla.

VV.AA. (2009), Elenco de Grandezas y Títulos Nobiliarios Españoles, Madrid, Editorial Hidalguía.

Fecha de recepción del artículo: 26 de diciembre de 2016

Fecha de aceptación y versión final: 8 de febrero de 2017 
